\title{
Abortamento na Adolescência: Atuação de Psicólogas em Hospitais-Maternidade Públicos de Salvador, Bahia
}

\author{
Maria Alice Ramos Ferreira Leal ${ }^{1}$ \\ ${ }^{1}$ Escola Bahiana de Medicina e Saúde Pública, \\ BA, Brasil.
}

\author{
Marilda Castelar ${ }^{1}$ \\ ${ }^{1}$ Escola Bahiana de Medicina e Saúde Pública, \\ BA, Brasil.
}

Resumo: O abortamento configura-se em um grave problema de saúde pública. Estudos realizados nos serviços de atenção obstétrica terciária em Salvador, Bahia, sobre o desempenho dos profissionais de saúde junto a adolescentes em situação de abortamento, revelaram que pesam sobre elas uma série de estereótipos e desconhecimento de suas características. Contudo, tais investigações não abordaram de forma particularizada a prática da Psicologia. A presente pesquisa buscou caracterizar a atuação de psicólogas junto a adolescentes em situação de abortamento. Realizou-se um estudo qualitativo de caráter exploratório, mediante a Análise de Discurso de 14 entrevistas com psicólogas de seis hospitais-maternidade de Salvador. Pôde-se constatar que a atuação das psicólogas estava sustentada por referenciais teórico-conceituais, que possibilitavam lidar com a singularidade das adolescentes, em cada ato de escuta. A prática das psicólogas mostrou-se sintonizada com as diretrizes do Ministério da Saúde para humanização da assistência, todavia, parte das entrevistadas não conhecia integralmente os documentos oficiais produzidos pelo Ministério da Saúde, norteadores das práticas nesses espaços, sugerindo que os textos relativos às políticas públicas não estavam no rol dos seus principais interesses. Ao mesmo tempo, esse desconhecimento interroga o próprio empenho institucional na difusão de políticas públicas mais democratizantes. A pesquisa evidenciou que as psicólogas estão atentas às peculiaridades das adolescentes, mantendo-as em um campo de grande visibilidade. Foram também capazes de realizar uma leitura precisa de diferentes aspectos da violência institucional que incide sobre essas usuárias, em situação de abortamento. Assim, as atuações relatadas indicam um paradigma mais humanizador de assistência em saúde.

Palavras-chave: Adolescentes, Abortamento, Políticas Públicas, Psicologia. 


\title{
Abortion in Adolescence: Practice of Psychologists in Public Maternity Hospitals in Salvador, Bahia
}

\begin{abstract}
Abortion is a serious public health problem. Studies about the performance of health professionals with adolescents in situations of abortion, carried out in the tertiary obstetric care services in Salvador, Bahia, have shown that a series of stereotypes and a lack of knowledge about their characteristics lay upon those adolescents. However, such studies have not dealt with the praxis of Psychology in a particularized manner. The current research aimed to characterize the performance of psychologists on adolescents in situations of abortion. A qualitative exploratory study was carried out through the Discourse Analysis of 14 interviews with psychologists from six maternity hospitals in Salvador. It became evident that the performance of the psychologists was supported by theoretical-conceptual references, which enabled them to deal with the singularity of the adolescents, in each act of listening. It was determined that the practice of the psychologists is in tune with the guidelines of the Ministry of Health for the humanization of assistance. Nevertheless, some of the interviewees did not fully know the documents produced by the Ministry of Health - guidelines for the practice in these spaces - suggesting that the texts related to public policies were not among their main interests. At the same time, this lack of knowledge questions the institutional commitment for the diffusion of more democratizing public policies. The research showed that the psychologists are sensitive to the peculiarities of the adolescents, making them visible in the psychology field. They were also able to perform a precise reading on different aspects of institutional violence that affects these attendees in situations of abortion. Thus, the reported actions indicated a more humanizing paradigm of healthcare.
\end{abstract}

Keywords: Adolescents, Abortion, Public Policies, Psychology.

\section{Aborto en la Adolescencia: Actuación de Psicólogas en Hospitales-Maternidades de Salvador, Bahía}

Resumen: El aborto se configura en un grave problema de salud pública. Los estudios realizados en los servicios de atención obstétrica terciaria en Salvador-Bahía, sobre el desempeño de los profesionales de salud junto a adolescentes en situación de aborto, revelaron que pesan sobre ellas una serie de estereotipos y desconocimiento de sus características. Sin embargo, esas investigaciones no abordaron de forma particularizada la práctica de la Psicología. La presente investigación buscó caracterizar la actuación de psicólogas junto a adolescentes en situación de aborto. Fue realizado un estudio cualitativo de carácter exploratorio, mediante el Análisis de Discurso de 14 entrevistas con psicólogas de seis hospitales-maternidad de Salvador. Se pudo constatar que la actuación de las psicólogas estaba sustentada por referencial teórico-conceptuales, que les posibilitaban lidiar con la singularidad de las adolescentes, en cada acto de escucha. La práctica de las psicólogas se mostró sintonizada con las directrices del Ministerio de Salud para humanización de la asistencia, sin embargo, parte de las entrevistadas no conocía integralmente los documentos oficiales producidos por el Ministerio de Salud, orientadores de las prácticas en esos espacios, sugiriéndonos que los textos relativos a las políticas públicas no estaban en el rol de sus principales intereses. Al mismo tiempo, ese desconocimiento interroga el propio empeño institucional en la difusión de políticas públicas más democratizadores. La investigación evidenció que las psicólogas están atentas a las peculiaridades de las adolescentes, manteniéndolas en un campo de gran visibilidad. También fueron capaces de realizar una lectura precisa de diferentes aspectos de la violencia institucional que incide sobre esas usuarias, en situación de aborto. Así, las actuaciones relatadas indican un paradigma más humanizado de asistencia en la salud.

Palabras clave: Adolescentes, Aborto, Políticas Públicas, Psicología. 


\section{Introdução}

A gravidez não planejada e o abortamento realizado em condições inseguras são graves problemas que impactam na saúde pública em escala global. Em 2008, levantou-se o quantitativo de 22 milhões de abortos inseguros em todo o mundo, sendo que 97,0\% ocorreram nos países emergentes (Martins-Melo et al., 2014). O risco de morte por complicações de um abortamento inseguro é muitas vezes mais alto do que de um abortamento realizado por profissionais e em condições seguras. Estima-se que, no Brasil, ocorra cerca de um milhão de abortos por ano, ocasionando altas taxas morbimortalidade (Brasil, 2011).

A Norma Técnica de atenção humanizada ao abortamento, do Ministério da Saúde, assinalou uma tendência ao declínio dessa causa mortis no Brasil, entretanto, encontrou-se nos estados nordestinos a menor redução da taxa de mortalidade do país (Brasil, 2011). Em estudo de Martins-Melo et al. (2014), no qual foram analisados dados do período de 1996 a 2012, observou-se que o estado da Bahia apresentou a maior razão de abortos inseguros por nascidos vivos (53,6 abortos em 100 nascidos vivos) e, em Salvador, levantamentos identificam que, desde os anos de 1990, o abortamento permanece como a principal causa isolada de mortalidade materna, com adolescentes e jovens apresentando maiores riscos de morte (Brasil, 2011).

A Área Técnica de Saúde da Mulher (2009) e a Área Técnica de Saúde da Criança e do Adolescente (2005), do Ministério da Saúde (MS), têm criado políticas públicas em concordância com a legislação internacional e brasileira, a fim de assegurar o cumprimento dos direitos humanos nos casos de abortamento, entretanto, na prática, constatam-se dificuldades na efetivação de uma atenção humanizada, na medida em que o campo relacional entre profissionais de saúde e usuárias é constantemente tensionado por questionamentos acerca da criminalização do aborto, envolvendo, não raro, aspectos ligados à moralidade e religiosidade (Brasil, 2011); bem como a cultura institucional do locus de assistência obstétrica ao se voltar prioritariamente para os eventos relativos à maternidade, relegam as usuárias em situação de abortamento ao plano secundário (McCallum, Menezes, \& Reis, 2016).

Recentes estudos realizados em hospitais-maternidade públicos de Salvador constataram que os profissionais de saúde tinham percepções estereoti- padas sobre as mulheres em situação de abortamento, sobretudo em relação às adolescentes, que foram descritas de forma pejorativa e como as mais propensas à prática do aborto (Santos, 2014). Em um dos hospitais-maternidade levantou-se o dado de que a maioria dos profissionais, independentemente de categoria profissional, considerava inadequado uma jovem se tornar mãe antes dos 25 anos e $62,2 \%$ dos profissionais de saúde declararam-se contrários à descriminalização do aborto (McCallum, Menezes, \& Reis, 2016). Entretanto, nessas pesquisas a perspectiva da(o) psicóloga(o) quase não foi examinada, abrindo uma lacuna que enseja o estudo sobre sua atuação no âmbito dessa assistência.

Assim, o presente estudo se propôs a caracterizar a prática de psicólogas(os) que atuam em hospitais-maternidade da Rede Pública de Salvador, Bahia, através de suas percepções sobre os entraves e os desafios para a efetivação da Política de Humanização voltada para adolescentes em situação de abortamento, ao tempo em que buscou analisar a relação que as psicólogas estabeleciam entre o conhecimento e a prática, identificando a racionalidade que norteava o seu fazer, suas ações, bem como possíveis inovações e/ou experiências exitosas nesse segmento assistencial.

A atuação da(o) psicóloga(o) junto a adolescentes na situação de abortamento requer considerar toda a complexidade do evento, a partir da própria vivência sexual na adolescência, que, na maior parte das vezes, desperta nos adultos percepções autocentradas e alheias à visão de mundo das(os) jovens, colocando-as(os) num campo de invisibilidade. $\mathrm{O}$ Marco legal: saúde um direito de adolescentes (2005) e o Marco teórico e referencial: saúde sexual e saúde reprodutiva de adolescentes e jovens do MS (2007) não os veem como meros objetos de intervenção do Estado, da família ou da sociedade, mas os reconhecem como sujeitos de direito, sendo que o Marco Teórico, de 2007, avança no sentido de tomar como eixo norteador as definições acordadas na IV Conferência Internacional sobre a Mulher em Pequim (1995), as quais dão maior visibilidade à saúde sexual, descolando-a da saúde reprodutiva. A publicação destaca igualmente que a visão "adultocêntrica", que define o adolescente por "não ser adulto" implica, em última instância, na desvalorização das reais necessidades e interesses da(o) adolescente, desqualificando sua capacidade de escolhas, sobretudo às relacionadas à 
sua sexualidade e à vida reprodutiva, bem como à sua capacidade de realizar outros projetos enquanto sujeito social.

A perspectiva "adultocêntrica" exibe, com efeito, mais ambiguidade do que propriamente interdições inequívocas. O psicanalista Contardo Calligaris (2009) analisa o duplo vínculo que o adulto estabelece com o adolescente ao lhe reconhecer a maturação do corpo, com a concomitante alegação de sua imaturidade para a vivência sexual; ensina-lhe que a autonomia e a independência são valores altamente estimados na cultura, mas tenta mantê-lo subordinado, sob constante tutela. Calligaris (2009) destaca que a "moratória" imposta ao adolescente faz como que ele não se sinta reconhecido dentro do pacto social, desencadeando, por vezes, comportamentos transgressivos e impulsivos; impulsividade tem sido igualmente identificada no campo da sexualidade (Calligaris, 2009).

As condições para a vivência da sexualidade na adolescência são muito diversas, refletem diferentes realidades e desigualdades, não apenas socioeconômicas, como também de gênero, de cor/raça (Brasil, 2005; Brasil, 2007; Menezes, \& Aquino, 2009; Brasil, 2013). Com efeito, a gravidez na adolescência pode evidenciar contextos de vulnerabilidade social, seja pela falta de informação, seja pela inacessibilidade a serviços de saúde, seja pela carência de uma prática dialógica, cuja incidência se tem observado mais acentuadamente em camadas sociais menos favorecidas (Alves, \& Brandão, 2009). Deve-se salientar, entretanto, que a ausência de diálogos sobre a sexualidade na adolescência, independentemente de classe social, dificulta que as transformações corporais e as formas de emergência do desejo sexual ocorridas na puberdade encontrem significações no campo simbólico, colocando para $\mathrm{a}(\mathrm{o})$ adolescente a necessidade de produzir tais significações em ato, precipitando-a(o) numa vivência da sexualidade de modo impulsivo e irrefletido (Calligaris, 2009; Tavares, 1996).

Um estudo realizado em uma maternidade pública de Salvador (McCallum, \& Reis, 2009), no qual foi traçado o perfil sociodemográfico das adolescentes, identificou que "residência própria" e "independência financeira" não eram pré-requisitos para que elas vivenciassem a experiência de serem mães, sendo, com efeito, essa vivência, a operação (em ato) que adquiria, a posteriori, o valor simbólico de ingresso no mundo dos adultos.
A realidade do aborto entre jovens no Brasil revela igualmente grandes disparidades sociais. Dados de um estudo multicêntrico, realizado em diferentes capitais do país (Menezes, \& Aquino, 2009), evidenciaram que moças com renda familiar per capita e escolaridade mais elevadas informaram ter abortado, respectivamente, 4,6 e 3,8 vezes mais que as moças pobres e de menor escolaridade. Desse modo, a gravidez se mostrou pouco frequente entre moças de classes sociais mais favorecidas e a prática do aborto relativamente recorrente; ao mesmo tempo foi encontrada uma menor ocorrência de gravidez em moças provenientes de classes populares que alcançaram um maior nível de escolaridade que suas mães, não sendo, nesse contexto, afastada a hipótese do aborto como forma de contracepção (Menezes, \& Aquino, 2009). Com efeito, têm-se identificado uma fragilidade na interiorização das normas contraceptivas entre as adolescentes brasileiras. Há uma ausência de formação sobre a sexualidade, muitos não-ditos e pouco espaço de interlocução no contexto familiar e na escola, bem como nos serviços de saúde (Alves, \& Brandão, 2009).

Na perspectiva de melhor delimitar a atuação de psicólogas nesse cenário, foram considerados também os achados de uma pesquisa qualitativa, realizada pelo Conselho Federal de Psicologia, publicada com o título: Psicologia: uma profissão de muitas e diferentes mulheres (2013), na qual as pesquisadoras analisaram as reflexões e o silêncio das psicólogas sobre temas da contemporaneidade, que articulava o exercício profissional em Psicologia, a mulher e o feminino. Temas que não despertaram interesse ou que não surgiram espontaneamente nos grupos focais foram analisados pelas pesquisadoras como "invisibilidades"; dentre eles, destacaram-se o tema das relações raciais, que só emergiu pontualmente nos grupos nos quais havia representantes negras, bem como o tema das políticas públicas (Lhullier, Muller, Bonassi, \& Longhini, 2013; Bernardes, \& Lima, 2013)

A discussão sobre tais "invisibilidades" é de total interesse para o presente estudo, à medida que a problemática do aborto não pode prescindir de políticas públicas para o seu enfrentamento, ao tempo em que fechar os olhos ante ao racismo é não levar em conta que a maior mortalidade nos casos de aborto no Brasil encontra-se no universo de jovens negras, moradoras de bairros periféricos das cidades brasileiras. 


\section{Método}

O desenho metodológico do presente estudo caracterizou-se por ser uma pesquisa qualitativa, de caráter exploratório, com suporte teórico da perspectiva sócio-histórica e da psicanálise. A interpretação dos resultados foi empreendida a partir da teoria de Análise de Discurso, delimitada por pressupostos da arqueologia foucaultiana (Foucault, 2015). A leitura flutuante das entrevistas procurou destacar a dimensão de "acontecimento" de cada enunciado, tendo em conta sua particularidade, isto é, longe de querer homogeneizar a massa de enunciados, anulando possíveis diferenças e contradições, buscou-se, sobretudo, o desenho de configurações singulares em cada ato de fala (Foucault, 2015).

Após a aprovação do CEP, CAAE 33098814.0.0000.5544 e Parecer no 1.317.532, iniciou-se a seleção das participantes nos estabelecimentos públicos de atenção obstétrica terciária de Salvador, que contavam com psicólogas(os) em seus quadros de pessoal. Foram entrevistadas 14 psicólogas de uma população total de 18 profissionais de Psicologia, que atuavam em seis hospitais-maternidade, no intervalo de dezembro de 2015 a março de 2016, meses referentes à coleta dos dados. As entrevistas, registradas em áudio, seguiram um roteiro semiestruturado, composto de questões que visavam aferir a percepção das entrevistadas sobre os espaços de atuação, caracterização da sexualidade das adolescentes e das situações de abortamento, conceituação de uma prática humanizada, estratégias utilizadas no atendimento às adolescentes em situação de abortamento. Procurou-se conhecer o posicionamento pessoal das entrevistadas sobre a legalização do aborto e se esse posicionamento interferia na prática profissional.

Foram incluídas na amostra as psicólogas que atuavam na assistência e excluídas duas psicólogas com menos de um ano de atuação na área, bem como uma que afirmou não ter experiência com a temática. Outra psicóloga não foi entrevistada porque estava de férias no período da coleta de dados. Com exceção de duas entrevistadas, as demais conheciam a proponente da pesquisa de outros espaços da sua atuação profissional.

No momento de concluir a entrevista, era formulada uma questão que visava a avaliar o grau de interferência da aproximação pessoal da pesquisadora com as participantes do estudo. Assim, as duas participantes que não conheciam previamente a proponente da pesquisa referiram-se a sensações de muita tranquilidade e uma delas verbalizou ter sido prazeroso dialogar sobre o tema; as participantes que já conheciam a pesquisadora foram unânimes em enfatizar igualmente sensações de tranquilidade e de se sentirem bem confortáveis no decorrer da entrevista. Foi possível avaliar que a aproximação pessoal e profissional da pesquisadora com as participantes da pesquisa não exerceu nenhum efeito inibidor, mostrou-se, pelo contrário, um facilitador, tanto para o acesso às participantes no momento inicial, quanto no decorrer da coleta dos dados.

Todas as entrevistas foram realizadas em locais reservados, que garantiram o sigilo e a confidencialidade das entrevistadas. Assegurou-se às participantes da pesquisa, conforme a Resolução ${ }^{\circ}$ 466/2012 do Conselho Nacional de Saúde (CNS), total sigilo, inclusive, no uso posterior das gravações, conforme Termo de Consentimento Livre Esclarecido. Ainda, para efeito de preservação do sigilo, as participantes da pesquisa receberam nomes fictícios, inspirados em personagens femininos da mitologia grega, a fim de que suas falas pudessem ser evocadas no processo de análise e discussão dos resultados, sem identificação.

Do arquivo, que segundo Foucault (2015) emerge das palavras colhidas, pôde-se estabelecer a seguinte categorização: perfil sociodemográfico e trajetória profissional das participantes da pesquisa; os cenários de atuação; percepções das psicólogas sobre a adolescência (seus contextos, sexualidade e as situações de abortamento); percepções das psicólogas sobre a atuação dos profissionais de saúde diante das situações de abortamento; posicionamento das psicólogas sobre a legalização do aborto; atuação das psicólogas nas políticas públicas voltadas para a humanização da assistência; atuação profissional (descrição das estratégias utilizadas).

\section{Resultados e discussão}

Pode-se afirmar que, no presente estudo, a massa de enunciados recolhidos foi quantitativa e qualitativamente espessa para atender ao critério de representatividade, permitindo desenhar o perfil sociodemográfico do conjunto das profissionais que atuam nesse segmento.

As 14 entrevistadas apresentaram idades entre 30 e 50 anos, sendo que onze delas estavam na faixa etária entre 30 e 37 anos, reproduzindo, de modo similar, a distribuição encontrada na pesquisa de 
âmbito nacional, cuja maior frequência de psicólogas (34\%) esteve na faixa etária entre 30 e 39 anos (Lhullier, \& Roslindo, 2013).

Quando a questão girou em torno da autodefinição da cor e da raça, as respostas das entrevistadas seguiram a padronização adotada pelo Instituto Brasileiro de Geografia e Estatística (IBGE) de modo espontâneo. Assim, oito psicólogas se autodenominaram brancas, cinco pardas e uma negra, refletindo um dado já conhecido, referente à maior prevalência de brancos no ensino superior no Brasil. Além disso, tal dado reproduziu a mesma curva estatística do levantamento relativo às psicólogas brasileiras, realizado pelo Conselho Federal de Psicologia, em 2013 (Lhullier, \& Roslindo, 2013). Quanto à naturalidade, observou-se um expressivo número de psicólogas das regiões Sul e Sudeste, todavia não foi indicador de que, neste segmento específico, postos especializados no Nordeste estivessem sendo ocupados por profissionais procedentes do Sul e Sudeste do Brasil, haja vista que a maioria destas psicólogas fizeram suas formações universitária e complementar em Salvador; apenas duas já vieram formadas de seus estados de origem, sendo que uma delas obteve o título de especialista na Universidade Federal da Bahia.

Em relação ao estado civil: oito são casadas; uma declarou ter uma união estável; três são solteiras; e duas divorciadas. Quatro das entrevistadas não têm filhos; sete têm filhos únicos; e três declararam ter dois filhos. No que diz respeito à religiosidade: seis psicólogas afirmaram não ter religião; uma afirmou ser judia não praticante; três são católicas; uma espiritualista; uma budista; uma protestante; e uma entrevistada afirmou que sua religião transitava entre o catolicismo e o espiritismo (o aspecto religioso será retomado no decorrer da análise).

Todas as entrevistadas fizeram uma formação complementar à graduação. A bagagem profissional das psicólogas revelou diversificados percursos: algumas desenvolveram e continuam a desenvolver suas práticas em distintos segmentos no espaço público; outras puderam se reportar às vivências em organizações privadas e/ou experiência de clínica particular. Desse modo, vários enunciados que visaram a caracterizar a prática que se desenrola no contexto da atenção obstétrica foram articulados às vivências e a modelos de intervenção em outros espaços de atuação.
A estruturação dos hospitais-maternidade como espaços hierarquizados, nos quais o discurso médico detém a hegemonia, coloca questões para as psicólogas sobre as possibilidades de coabitação com esse campo discursivo, na construção de um paradigma de saúde que não se reduza ao modelo biomédico. A estreiteza da concepção de saúde, baseada no referido modelo, acaba por precarizar as condições de trabalho nesses espaços, sobretudo para profissionais que se voltam para as subjetividades, cujas práticas não são consideradas prioritárias nas diferentes esferas de gestão. Assim, Themis (M.5) narrava que a perda de espaço físico na instituição (o que foi constatado pela própria dificuldade de encontrar um local para a realização da entrevista) havia impossibilitado, por exemplo, dar seguimento a um projeto que ocorria semanalmente, durante uma hora, com o objetivo de fazer a palavra circular entre os profissionais sobre temas diversos que estivessem impactando no dia a dia daquela maternidade.

A limitação de espaço físico pode instaurar igualmente uma condição de violação de direitos para as usuárias, como foi destacada pelas entrevistadas que sinalizaram a ausência de garantias quando à privacidade; em outras situações, a própria distribuição das pacientes nesses espaços se configurou em violência institucional, como sobressai nos relatos: "Às vezes, aqui na enfermaria, a prática de colocar [mulheres no pós-abortamento] no mesmo quarto [com mulheres] com outros bebês... E isso mesmo que não seja algo tão intencional, mas acaba sendo uma agressão" (Nice, M.1).

O questionamento sobre a pouca adequação dos espaços físicos às necessidades das usuárias e das próprias profissionais sinaliza que o conceito de ambiência definido pela Política Nacional de Humanização - PNH (Brasil, 2010), como tratamento dado ao espaço físico a fim de proporcionar atenção acolhedora, resolutiva e humana, necessita ainda ser materializado. A PNH considera que a ambiência exerce efeitos sobre as relações interpessoais, podendo favorecê-las ou dificultá-las em certa medida. Apenas na M.2 já existe uma enfermaria ambientada para as adolescentes, cujos leitos estão separados em boxes com cortinas, a fim de proporcionar maior privacidade às usuárias. Nice, em sua fala, considera que a prática de colocar mulheres no pós-abortamento juntamente com mulheres alojadas com seus recém-nascidos se configura como uma 
agressão, "mesmo que não seja algo tão intencional"; o vocábulo "tão", modulando a intensidade, passa a ser indicador de alguma intencionalidade ainda que subliminar. Outra questão relevante quanto à "unidade de espaço" não passa despercebida por uma das entrevistadas, a saber: a naturalização de hospitais-maternidade como locais para o atendimento a mulheres adultas e adolescentes em situação de abortamento. Higia (M.4) comenta:

Se dissesse assim: Qual é o sonho da unidade hoje? É da gente ter um pronto-atendimento onde essas mulheres pudessem ser atendidas especificamente; pudessem ter uma alta mais rápida, tipo hospital-dia, que pudesse ter uma rotatividade maior, um período de permanência menor e [que as mulheres] entrassem o menos possível em contato com a maternidade. Até isso a gente pergunta na nossa pesquisa aqui interna. O símbolo da Maternidade é uma adolescente grávida, barriguda. São símbolos que tão implícitos [...] a gente vai ter que olhar e dizer assim: Poxa! Como é pra você que está numa outra condição, estar neste espaço?

Higia mostra-se alerta ao fato de que a usuária em situação de abortamento se encontra - nesse cenário - em "outra condição", pois não vivencia os eventos símbolos de uma maternidade (gestação, parto e puerpério). Assim, percebe-se que nas situações de abortamento, trata-se mais de subverter a lógica que define, literalmente, a arquitetura desses espaços, que de adequá-los simplesmente, na medida em que eles são efeitos de uma racionalidade que estrutura formas e fluxos de cuidados que excluem, ainda que sem intencionalidade, as mulheres adultas e adolescentes em processo de abortamento do atendimento prioritário (McCallum, Menezes \& Reis, 2016). A estética não é "inocente" (à medida que ela não é inócua): veicula mensagens e valores de modo subliminar, como destacava Higia ao evocar o próprio símbolo da Maternidade na qual ela trabalha. Por essa razão, a PNH considera que a dimensão estética possibilita o surgimento de formas de subjetivação e de leituras que constroem realidades; nesse sentido, os serviços de saúde deveriam favorecer uma estética que seguisse o fluxo criativo que advém de uma ética da escuta, isto é, que dá voz e valoriza a produção de todos os atores envolvidos no campo da saúde. Logo, à pergunta de Higia "como é para você estar nesse espaço?", sendo respondida pela usuária, possibilitaria a emergência, talvez, de uma nova estética.

\section{Adolescências: "con-textos"}

A pluralidade de vivências, em decorrências de múltiplos fatores - sociais, econômicos, entre outros - fez algumas entrevistadas destacarem a noção de "adolescências" em lugar de optarem por falar de uma "adolescência" como um conceito imutável e de fácil aplicação em diferentes contextos. Artémis (M.2) avalia que o grau de maior ou menor dependência dos adultos é o que determina a condição "adolescente"; a autonomia passa a ser, em detrimento do critério cronológico, a senha para ingresso na vida adulta. Higia (M.4), por sua vez, percebe a diversidade de adolescências através dos diferentes projetos de vida que divergem dos padrões e modelos idealizados do profissional de saúde, que normalmente, sendo oriundo de outro contexto sociocultural e econômico, não percebe que suas referências não são universais e que, por isso mesmo, não podem ser impostas como “verdades" absolutas. Higia reporta-se ao próprio choque cultural "Como assim uma gravidez planejada com 16, 17 anos?” e à necessidade que teve de olhar através de outras lentes para desvelar realidades de "adolescências" que se mantinham para ela imersas em opacidade.

Moira (M.3), nessa mesma perspectiva, traça o perfil de duas realidades socioeconômicas nas quais se inserem as(os) adolescentes, destacando vulnerabilidades sociais que determinariam projetos de vida, que culminam com a gravidez na adolescência.

Então [...] já atendi muitas meninas que chegaram aqui no ambulatório pra me dizer estavam grávidas porque queriam, porque planejaram, porque queriam formar uma família, porque queriam sair da casa da mãe, que não aguentava mais morar numa casa com 10, 12 irmãos, porque não aguentava mais o padrasto que batia, porque não aguentava mais o padrasto que abusava, porque não aguentava mais a mãe que a mandava tomar conta da casa e cuidar dos irmãos, enfim, que não aguentava a vida que tinha e pra mudar daquela vida, pra sair daquela realidade, a única solução era uma gravidez, porque ali ela ia ser 
vista como mulher, responsável, né? E ainda ela ia poder sair daquela casa, pra passar pra outro lugar pra morar, e elas estavam aqui aparentemente muito bem resolvidas (Moira, M.3).

A entrevistada depreende que, diante de tantos obstáculos, a gravidez passa a se configurar como "única solução" para a adolescente escapar de um cenário marcado pelo "não ter" (moradia, privacidade, respeito, afeto) e a maternidade se configurando como possibilidade de "ter", produzir, engendrar algo intrinsicamente pessoal: seu filho, sua criação. Assim, a potência biológica materializada na função procriadora, para Moira, vem responder às demandas de reconhecimento e aos anseios de mobilidade e ascensão social das adolescentes.

Algumas entrevistadas tiveram dificuldade para evocar os casos de adolescentes em situação de abortamento, revelando que a frequência deles não tem sido tão expressiva a ponto de suplantar a experiência que as profissionais têm com adolescentes grávidas ou no puerpério, no contexto dos hospitais-maternidade. Hebe (M.3) observa: "[...] Eu tive muito mais experiência de um filho desejado, no mínimo, do que de filho indesejado na adolescência, por incrível que pareça". O parecer "incrível" que a gravidez possa ser desejada ou até mesmo planejada, nesse momento da vida, faz sobressair o quanto o estereótipo que atinge as adolescentes (como mais propensas ao aborto) está presente no imaginário social, sem excluir o profissional de saúde, que reproduz de modo irrefletido tais construções do senso comum, conforme alguns estudos já identificaram (McCallum, Menezes \& Reis, 2016; Santos, 2014).

Na tentativa de desmistificar a falsa crença que as adolescentes são as que mais abortam, as psicólogas da M.4 realizaram um levantamento sociodemográfico das usuárias da maternidade, a fim de gerar um dado concreto que permitisse à equipe desconstruir a imagem distorcida que detinha do seu público de adolescentes. Com efeito, os números encontrados confirmaram os achados da última pesquisa sobre abortamento, realizada em âmbito nacional pelo MS, com mulheres escolarizadas de 15 a 49 anos, na qual se constatou que o aborto foi crescente com a idade (Brasil, 2009). Outro aspecto levantado pelas entrevistadas, diz respeito ao início da atividade sexual diferindo quanto à inclusão em certo estrato social. Ariadne (M.5) aponta:
Atendo mais adolescentes fora daqui do que aqui [...] E na Clínica, todo mundo que eu atendi teve um início de vida sexual posterior, não foi aos 14 , nem aos 15 , foi mais perto dos 18,19 ou com 20 ainda não teve. Enquanto que aqui, a gente vê meninas mais jovens assim 14, 13, 15, né?

Na tentativa de desemaranhar essa questão, Iris (M.1) pondera que há uma ausência de diálogo como efeito de uma "dificuldade", de um "constrangimento" para abordar o tema da sexualidade, ainda considerado tabu na sociedade, ela realça o prisma supostamente adulto que reprime e julga a precocidade da vivência sexual na adolescência e não percebe as próprias limitações para afrontar o diálogo sobre sexo; ademais, envia permanentemente dupla mensagem aos adolescentes (Calligaris, 2009).

Algumas entrevistadas vão destacar a proeminência da figura materna relegando a adolescente ao plano secundário. Artémis (M.2) pontua que "por questões delas", as mães são muitas vezes invasivas, na medida em que não respeitam o espaço subjetivo das filhas adolescentes. Gaia (M.2) faz ainda uma distinção entre a posição subjetiva da adolescente grávida ou puérpera daquela da adolescente em situação de abortamento: em que pese sobre as primeiras o controle da figura materna, essas adolescentes acabam por ter uma margem maior para se colocar de forma menos passiva, sendo mais capazes de reivindicar a autoria de suas próprias experiências.

A psicanalista Marie-Magdeleine Chatel (1995), que escutou mulheres que decidiram pela Interrupção Voluntária da gestação (IVG), desde o início dos anos 1970 até 1992, isto é, um pouco antes e após a legalização do aborto na França constatou certo aspecto, em relação às mulheres que ela atendia nas situações, que faz ecoar a observação de Gaia quanto à passividade das adolescentes nos casos de abortamento, isto é: a ausência subjetiva das mulheres que, naquela situação, pareciam carregar o próprio corpo como se fosse um "móvel", quase nunca escutavam quando o próprio nome era chamado, como se o sujeito não estivesse presente. A adolescente, ao abdicar do protagonismo de seu ato, permanece como expectadora, vendo a cena transcorrer entre adultos como se eles fossem os principais atores do drama. Além dessa condição, outros sentimentos podem ser experimentados pelas adolescentes, como evocam as entrevistadas, na busca de melhor caracterizá-las. Destacam: 
[...] muito mais comum o alívio do que certo pesar. No aborto provocado, enfim, era do desejo e isso faz sentido, mas muitas vezes no aborto espontâneo, principalmente em adolescentes, é muito raro um adolescente ter um pesar sobre o bebê que não vingou (Artémis, M.2).

[...] Acaba sendo um alívio pra família "ah, você é muito nova", "que bom não levou adiante... poderia ser um bebê com problemas". Mas, eu sei que no fundo essa mulher quando você a escuta, ela queria aquela gravidez, teve o desejo... É algo que não é aceito socialmente, mas que tem aí um desejo que não pode muitas vezes ser falado, porque é como se ela não pudesse vivenciar o luto, a morte desse bebê... é um luto não antecipado, né? (Irene, M.6).

Respaldadas em suas escutas, as psicólogas destacam uma borda pela qual se pode ter acesso à particularidade do evento subjetivo para cada adolescente: Artémis (M.2) confrontou-se com adolescentes que experimentaram mais "alívio" que "pesar". Essa percepção é nuançada por outras leituras, como o faz Irene (M.6) ao destacar que o sentimento de "alívio" comparece mais frequentemente na família, que não autoriza a adolescente vivenciar o seu luto. Na percepção dos adultos, o aborto teria sido o melhor desfecho e a adolescente acaba por silenciar seu "desejo" e seus próprios sentimentos. Mas a oferta de uma escuta que, como particulariza Chatel (1995), rompe com o tom "velado e asséptico" do atendimento, possibilita e autoriza a adolescente expressar o que não é "socialmente aceito" e a vivenciar o seu luto ou o seu alívio. A acolhida subjetiva do embrião intraútero não se faz sem ambivalência, daí decorre o "alívio" após o abortamento de uma gravidez desejada e o "luto" após um abortamento provocado. Leda (M.1) destaca não apenas a dimensão do luto - tanto no abortamento espontâneo como no provocado -, mas também a vergonha, o medo do julgamento do profissional de saúde e o medo do julgamento da família. Assim, revela-se uma multiplicidade de sentimentos nas situações de abortamento, cuja variabilidade é determinada pela vivência singular do evento. Todavia, tais sentimentos podem ser intensificados pela forma como as adolescentes são recebidas nos serviços de saúde. Tésis (M.2) relata que já constatou expressões, verbalizações de alívio por parte das usuárias no momento da alta, não simplesmente em razão da realização do procedimento, mas por estarem deixando para trás a própria experiência de hospitalização.

Para poder melhor aferir a visão das psicólogas acerca do tratamento dado às adolescentes, foi-lhes questionado se elas percebiam algo das relações raciais perpassando os atendimentos. A maioria das entrevistadas teve dificuldades de identificar a questão da raça/cor isolada do contexto social e das vulnerabilidades que afetam historicamente a população negra no Brasil. Contudo, elas destacaram outras condições que são estigmatizadas pelo profissional de saúde, tais como, ser morador de rua, ser usuário de álcool e/ou outras drogas, ser portador de transtorno mental, diferir quanto orientação sexual heterossexual e algumas entrevistadas sinalizaram a discriminação à adolescente sexualmente ativa. Seguem falas do arquivo: "Eu vejo diferença no tratamento em relação à idade da mulher. As adolescentes, eu percebo que elas são mais julgadas [...] Eu vejo essa marca muito forte" (Íris, M.1).

Não consigo perceber [discriminação racial], pode ser que tenha. Acho que tem mais a ver com a história mesmo daquela mulher [...] acho que o preconceito está muito mais se ela provocou um aborto, se ela não provocou [...] Se ela rejeita o filho, se ela usa drogas [...] se ela tem mais de um filho... Eu acho que aí sim, tem (Irene, M.6).

Desse modo, a pergunta sobre o atravessamento da questão racial no âmbito da assistência resvalou para uma série de outros estigmas e preconceitos, alimentados por juízos de valor que avaliam situações e contextos a partir de um sistema de poder, produtor de "verdades" (do que é normal, do que é anômalo), estruturado pela hegemonia de um regime político, econômico e social (Foucault, 2006) que dita as regras nesse cenário institucional, fazendo incidir sobre as situações de abortamento, na maioria das vezes, um julgamento ainda mais severo. Expõem as entrevistadas:

Acho que o grande problema é o julgamento [...] Tal paciente não provocou [o aborto], então é melhor do que a paciente que provocou. $\mathrm{Ou}$ eu sou melhor do que a paciente que provocou, né? Porque no fim é isso, eu ser mais [...] Se coloca julgando o outro (Dione, M.4). 
Talvez [o entrave] seja esse medo do julgamento [...] elas já saem de casa, eu acho, esperando chegarem para serem julgadas, em situação de aborto provocado [...] E você, enquanto membro daquele hospital de alguém que já julgou, você passa também a ser uma julgadora por tabela, né? Então eu acho que pra você mostrar que você tá ali pra dar o suporte e não pra julgar, é um desafio. Conquistar essa confiança é um desafio (Moira, M.3).

Dione destaca na ação de julgar o embate de puro prestígio de consciências que visam, em última instância, ao reconhecimento do outro ("sou a mais ética" "a mais correta"); os efeitos dessas disputas repercutem no trabalho da equipe multiprofissional e na atuação específica da(o) psicóloga(o) aí inserida(o). Em geral, a equipe de saúde costuma dissociar os procedimentos técnicos e a vivência interpessoal que emerge dos atos de assistência, o que acaba por redobrar demandas para a intervenção psicológica. Desse modo, no contexto das situações de abortamento, a(o) psicóloga(o), além de ter que lidar com as questões suscitadas para os sujeitos singularmente, terá que contornar as formas iatrogênicas de intervenções da equipe que ignora tanto a dimensão política, quanto a dimensão da subjetividade no seu fazer profissional, produzindo efeitos deletérios à saúde mental, colocando para as(os) psicólogas(os), como destaca Moira, um grande desafio para a atuação profissional.

As entrevistadas se reportam a outros aspectos que interferem na implementação de uma atenção humanizada, precisamente a dimensão subjetiva do abortamento para cada membro da equipe multiprofissional que, inevitavelmente, se reflete na assistência. Sublinharam alguns fatores que devem ser descritos e analisados. Íris (M.1) destaca a "mistura" que o profissional de saúde faz entre os seus valores e crenças e o trabalho mais técnico. Diz:

Claro que a gente não vai entrar como uma tábula rasa, a gente não vai entrar despido completamente dos valores, das crenças, das ideias. Mas, eu acho que, muitas vezes, o profissional não se dá conta disso, do quanto as coisas estão misturadas e aí ele acaba atuando baseado nesse julgamento, nesse juízo de valor que ele faz (Íris, M.1).
O fato de o profissional de saúde "não se dar conta" do quanto seus valores, suas crenças, suas ideias formam um sistema ideológico que o faz operar - seja através de gestos ou atitudes, seja pela tomada de decisões - desencadeando efeitos de dominação (Foucault, 2007; Brandão, 1990) sobre as(os) usuárias(os) dos serviços de saúde, denuncia a pouca reflexão sobre a natureza política de sua prática e o alheamento quanto ao papel que tem a sua subjetividade no campo assistencial. Analisando por esse ângulo, Dóris (M.2) constata a necessidade de trazer para o espaço público as questões ligadas ao abortamento, destacando a importância de falar, discutir o mais abertamente possível tudo o que a ele está relacionado e considera um entrave mantê-lo atrelado à religião, à criminalização e à moralidade.

Dóris compreende que ao discurso moralizador subjazem questões de ordem pessoal que poderiam se tornar mais dolorosas pela aproximação com as adolescentes em situação de abortamento. A entrevistada faz a hipótese de que, sendo mulheres o maior contingente de trabalhadores em uma maternidade, não seria improvável que muitas dessas profissionais já tivessem, elas próprias, vivenciado alguma situação de abortamento. Trata-se de uma conjectura plausível, considerando que a Organização Mundial de Saúde estima que uma, a cada nove mulheres, recorre ao abortamento para interromper uma gravidez não planejada; além disso, o percentual de abortos espontâneos exibe taxas igualmente significativas (Brasil, 2011).

Themis e Ariadne, da M.5, por sua vez, compartilham a percepção de que não eram chamadas, na maioria das vezes, para prestar atendimento psicológico às mulheres adultas e adolescentes em situação de abortamento, como se elas estivessem "invisíveis". Todavia, trata-se mais de invisibilizá-las do que não as ver propriamente. As entrevistadas relataram igualmente que percebiam diferenças na assistência prestada quando o aborto é espontâneo ou provocado. Tésis (M.2) afirma: "Ah, sim, sim. Com certeza. E às vezes o espontâneo gera dúvidas, suspeitas. Acho que quando chega um abortamento especificamente já gera inquietação na equipe”. A "inquietação" que atinge a equipe testemunha o quanto os profissionais podem ser afetados com a ocorrência do aborto e a suposta invisibilidade surge como uma manifestação encobridora de outros afetos. A premissa, às avessas, de que, "a princípio, todo aborto é provocado, até 
que se prove o contrário", produz intenso sofrimento para as mulheres adultas e adolescentes que abortam espontaneamente, amplificando os sentimentos que eclodem nessas situações.

Gaia (M.2) analisa aspectos da violência obstétrica nas situações de abortamento, realçando o texto que aí transcorre de modo subliminar, o qual, além de mergulhado em um profundo desconhecimento das raízes sociais do problema, parece se embasar na crença do senso comum de que ações punitivas seriam capazes de exercer um efeito "corretivo". Assim, a analgesia não é feita, ou dirigem-se falas irônicas à usuária, a exemplo de, "até o ano que vem", porque se a experiência ocorresse de modo indolor, poderia ser encarada como incentivo, avalia Gaia. Com efeito, são violências físicas e psíquicas que exorbitam em poder, rompendo com a própria lógica disciplinar que norteia o hospital moderno, a partir do final do século XVIII (Foucault, 2007; 1998; 2014).

Gaia (M.2) avalia ainda que sobressaem mais nitidamente, no relato das mulheres adultas do que na fala das adolescentes, as diferenças na assistência prestada em função de abortos provocados ou espontâneos. As adolescentes parecem, para a entrevistada, ter maior dificuldade para verbalizar a violência à qual são submetidas: percebe, por um lado, uma postura antagônica de algumas delas em relação à equipe, outras, ao contrário, colocam-se em uma posição submissa de ouvir sem questionar, sendo raras, em sua observação, as que dialogam e reivindicam o direito de ser bem acolhidas, tendo ou não provocado o aborto.

As entrevistadas destacaram que interlocução entre as usuárias e os profissionais de saúde pode ser atravessada por aspectos limitantes, advindos de outras esferas; alguns deles incidem diretamente sobre as adolescentes, como, por exemplo, a realidade de um ensino deficitário; bem como, a fragilidade da rede de saúde impactando no processo educativo, voltado para a promoção da saúde. Íris (M.1) refere-se à dificuldade de mapear a rede para realizar encaminhamentos para as Unidades Básicas de Saúde após a hospitalização; e os encaminhamentos são feitos sem a garantia de que $\mathrm{o}$ atendimento será realizado.

Elencadas todas essas limitações, as entrevistadas também se reportaram aos avanços resultantes da Política Nacional da Rede Cegonha - RC (Portaria No 1.459, 2011), cujas diretrizes voltadas para a humanização da assistência perinatal alcançaram, parcialmente, mulheres em situação de abortamento.
A diretriz, por exemplo, que garante a presença do acompanhante durante o trabalho de parto acabou por beneficiar as usuárias em caso de abortamento.

Sabe-se que resultados positivos na prestação dos serviços são obtidos a partir da melhoria dos processos de trabalho, daí surge o interesse em delimitar a participação das psicólogas na construção desses modelos de assistência, a fim de caracterizar de suas atuações.

\section{A "unidade de ação": as psicólogas e a dimensão do abortamento}

Foram endereçadas às entrevistadas duas questões inter-relacionadas: a primeira, se elas tinham algum posicionamento pessoal sobre o aborto; a segunda, se esse posicionamento interferia em suas atuações profissionais, a fim de explorar o alcance do abortamento sobre as subjetividades e o seu efeito no exercício profissional, sobretudo quando se está demasiado próximo de sua ocorrência.

Das 14 entrevistadas, 10 se declararam a favor da legalização, algumas foram enfáticas quanto ao direito e às prerrogativas da mulher ao próprio corpo; as religiões professadas não foram impeditivas à adesão aos argumentos que descriminalizam o aborto, sendo que muitas frisaram que não se viam aderindo à prática do abortamento do ponto de vista pessoal. Legalização do aborto é vista por Artémis (M.2) como uma possibilidade de falar antes de se lançar em ato, colocando a perspectiva de uma tomada de decisão mais refletida e elaborada, o que em muito reduziria as precipitações que caracterizam as passagens ao ato, bem como a realização do aborto em condições inseguras, responsável pelos altos índices de mortalidade materna. Seguindo a linha de raciocínio adotada pelas "Católicas pelo direito de decidir", (2016), Artémis reporta-se à doutrina do livre arbítrio para demonstrar a fragilidade e incoerência interna do posicionamento religioso, a partir do Cristianismo, que nega às mulheres a possibilidade de escolha quanto aos seus atos.

Foi igualmente evocado pelas entrevistadas o argumento de que a descriminalização possibilitaria uma melhor assistência, no sentido de que o profissional de saúde poderia ser menos afetado ao ver-se desonerado de lidar com um evento considerado ilegal, que o faz questionar ou se sentir questionado sobre a legalidade de sua prática, ao mesmo tempo em que atos discriminatórios poderiam se tornar menos "aceitáveis" socialmente, como se reporta Ariadne 
(M.5), exemplificando que talvez a mulher não fosse tão deixada de lado ou passasse a ser chamada pelo nome e não mais como "aquela cureta"; ou seja, a violência institucional poderia ser mais bem coibida.

As entrevistadas que se posicionaram a favor da legalização do aborto também destacaram a necessidade de políticas públicas que respaldassem e amparassem mulheres adultas e adolescentes em suas decisões, como também foi ressaltada a importância de se priorizar a prevenção. Higia (M.4) insistiu na necessidade de "investir em alternativas para as escolhas", tanto através da garantia do planejamento reprodutivo, como pela garantia de um "aparato social para as mulheres que não tivessem condições de levar sua gravidez adiante". Sobressai um enunciado que se mostrou favorável ao aborto, não apenas em função das proporções que o evento toma em termos de saúde pública, mas por ser uma ocorrência subjetiva, cuja legalização traria garantias quanto aos direitos individuais. Argumenta:

[...] como os métodos não são $100 \%$ e nem a gente é $100 \%$, [...] você falha, o inconsciente falha [...] Eu acho que é muito complicado se ter um filho sem querer e sem ter condições. [...] Mesmo que fosse uma só pessoa que morresse e a realidade fosse diferente, eu seria a favor da escolha da mulher (Dione, M.4).

A perspectiva introduzida por Dione (M.4) aponta para a condição do sujeito dividido constitutivamente; a dimensão do inconsciente, evocada pela entrevistada, relembra que o sujeito não tem o controle absoluto sobre o seu agir, que ele falha em suas determinações e que muitas vezes é assolado pela ambivalência entre desejos não confessos e as exigências de um ideal que erguem defesas na tentativa de mantê-los silenciados. Assim, este argumento parece problematizar o abortamento na interface ético-política, reivindicando um direito moral, "mesmo que fosse uma só pessoa que morresse", não restrito à natureza de um direito puramente legal, situado na esfera pública (Pires, 2016).

As entrevistadas que não se posicionam francamente a favor da legalização não foram, todavia, radicalmente contra; expressaram mais dúvidas que convicções acerca do assunto. Assim, os enunciados tecidos pelas entrevistadas foram homogêneos em destacar a importância de não julgar, de se colocar o mais abertamente possível, disponível para acolher as decisões, os posicionamentos e as escolhas do outro.

Ao responder o questionamento sobre o que seria mais importante na direção do atendimento psicológico às adolescentes em situação de abortamento, Leda (M.1) vai enfatizar a necessidade de centrar-se na "sabedoria prática" (Ayres, 2000), por assim dizer, à medida que ela traça uma distinção entre a sua prática e a lógica instrumental que rege as ações no contexto da saúde, enfatizando que seu fazer profissional não se orienta pela racionalidade instrumental biomédica, que procura obter tão somente "êxitos técnicos" (Ayres, 2007).

$\mathrm{O}$ atendimento psicológico, para as entrevistadas, oferece as condições para que a adolescente na situação de abortamento expresse a ambivalência, a mescla de sentimentos e a possibilidade de ressignificar o evento. Assim, a partir de diferentes bordas de aproximação ao fazer profissional, os enunciados das entrevistadas mostraram-se sustentados por um referencial teórico-conceitual que lhes permitiria lidar com cada situação de modo singularizado (que descarta a aplicação mecânica de métodos ou técnicas), evidenciando que estavam orientadas pela racionalidade da práxis (Campos, 2011).

As entrevistadas também valorizaram os espaços colegiados. Na M.4, fundamentadas na Norma Técnica (Brasil, 2011), as psicólogas há dois anos participam do Colegiado Gestor buscando dar visibilidade às questões envolvidas nas situações de abortamento, procurando introduzir mudanças nos fluxos, de modo que impactem positivamente em todo processo de trabalho e na assistência, consequentemente. Puderam destacar algumas mudanças em práticas e rotinas já obtidas, a exemplo da pergunta que era feita acerca do motivo da internação, na chegada ao serviço, ainda na recepção, e que foi retirada da ficha de admissão. A usuária naquela situação se via impelida a responder, diante de todos os olhares, que se encontrava em situação de abortamento, o que causava uma exposição e um constrangimento inteiramente desnecessários. Desse modo, interferir, discutir os fluxos, participar das decisões colegiadas tem sido prioritariamente a estratégia adotada por algumas psicólogas para oferecer uma assistência humanizada às usuárias na situação de abortamento.

Ao término das entrevistas, pôde-se constatar que apenas quatro entrevistadas conheciam a Norma Técnica de atenção humanizada ao abortamento produzida pelo MS, incidindo sobre esta amostra algo 
da configuração traçada por Bernardes e Lima (2013) na análise das falas de psicólogas das cinco regiões brasileiras, na qual o tema das políticas públicas foi categorizado como "invisibilidades", por não ter despertado interesse ou por não ter surgido espontaneamente. A invisibilidade das políticas públicas parece incidir não apenas nas(os) psicólogas(os), mas no profissional de saúde de modo geral, refletindo o que alguns autores consideram como alienação no serviço público. Mattos (1994), analisando essa problemática, vai destacar que a referida alienação serve, sobretudo, às elites e às corporações que parasitam o Estado buscando tornar suas instituições ineficientes - de modo a enfraquecê-lo, a fim de fazer prosperar o modelo neoliberal.

\section{Considerações finais}

A investigação permitiu evidenciar, no discurso das participantes da pesquisa, o lugar de destaque dado às diretrizes do acolhimento e do não julgamento, preconizadas pela Atenção humanizada ao abortamento: norma técnica (Brasil, 2011); as psicólogas foram unânimes em destacar a necessidade de se criar um espaço que propiciasse a elaboração de questões relativas à sexualidade, ao desejo de ser ou não ser mãe e à apropriação subjetiva da experiência do abortamento.

Curiosamente, observou-se que apenas quatro participantes da pesquisa conheciam integralmente a Norma (Brasil, 2011), entretanto, foi notável a estreita sintonia entre as atribuições nela previstas e as práticas desenvolvidas pelas participantes da pesquisa, o que evidencia, por um lado, a pertinência das atribuições aí colocadas, de forma coerente com os fundamentos do exercício profissional em Psicologia; por outro, denuncia, paradoxalmente, o pouco interesse das psicólogas que exercem suas práticas no campo da saúde pública, acerca dos documentos oficiais que delineiam a sua atuação. Este dado reflete os achados da pesquisa de âmbito nacional, realizada pelo Conselho Federal de Psicologia, em 2013, na qual as políticas públicas foram consideradas como uma das "invisibilidades" na caracterização da psicóloga brasileira, por ser uma temática periférica, sem força de enunciabilidade. Ademais, esse dado pode levantar questionamentos acerca da própria estrutura institucional, quanto ao seu possível interesse ou desinteresse na disseminação de políticas públicas mais democratizantes.

As participantes da pesquisa destacaram a importância de respeitar a autonomia das(os) adolescentes quanto aos seus direitos sexuais e reprodutivos, bem como foram capazes de identificar as vulnerabilidades no plano sociocultural e econômico a que estão expostas as adolescentes em situação de abortamento; além disso, realizaram uma leitura precisa das formas de violência institucional que incidem sobre essas usuárias.

Foram descritas estratégias que vêm sendo desenvolvidas para humanização da assistência, focadas no atendimento clínico à beira do leito ou no espaço ambulatorial, porém em algumas maternidades as psicólogas têm participado ativamente dos espaços colegiados, tentando contribuir para a otimização dos processos de trabalhos que impactam diretamente na humanização da assistência. Ressalte-se, ainda, que as psicólogas que se apropriaram efetivamente da Norma Técnica (Brasil, 2011), deram um salto qualitativo na perspectiva de uma clínica - de fato - ampliada e compartilhada, o que significa considerar a potência da produção coletiva para fazer emergir um paradigma de saúde mais humano no espaço público.

Desse modo, a presente investigação buscou contribuir para a reflexão de um tema ainda pouco explorado, abordando o fazer profissional, através de diferentes nuances, concepções e especificidades no lidar com adolescentes em situação de grande vulnerabilidade. As psicólogas, que ganharam voz nesse estudo, apontaram caminhos a serem percorridos em diferentes esferas para superação das dificuldades, dentre eles sobressai a descriminalização do aborto, como meio para afrontar - no espaço da polis - os problemas decorrentes de séculos de clandestinidade.

\section{Referências}

Alves, C., \& Brandão, E. R. (2009). Vulnerabilidades no uso de métodos contraceptivos entre adolescentes e jovens: Interseções entre políticas públicas e atenção à saúde. Ciência \& Saúde Coletiva, 14(2), 661-670. https://doi. org/10.1590/S1413-81232009000200035

Ayres, J. R. C. M. (2000). Cuidado: Tecnologia ou sabedoria prática? Interface - Comunicação, Saúde, Educação, 4(6), 117-21. https://doi.org/10.1590/S1414-32832000000100010 
Ayres, J. R. C. M. (2007). Uma concepção hermenêutica de saúde. Physis: Revista de Saúde Coletiva, 17(1), 43-62. https://doi.org/10.1590/S0103-73312007000100004.

Bernardes, A. G., \& Lima, M. L. C. (2013). Invisibilidades: As políticas públicas como potência de variação nas práticas em Psicologia. In: L. A. Lhullier (Org.), Psicologia: Uma profissão de muitas e diferentes mulheres (pp. 201-222). Brasília, DF: Conselho Federal de Psicologia.

Brandão, N. H. H. (1990). Introdução à análise do discurso. (7a ed.). Campinas, SP: Unicamp.

Brasil. (2005). Ministério da Saúde, Secretaria de Atenção à Saúde, Área de Saúde do Adolescente e do Jovem. Marco legal: Saúde, um direito de adolescente. Brasília, DF: o autor.

Brasil. (2007). Ministério da Saúde, Secretaria de Atenção à Saúde, Departamento de Ações Programáticas Estratégicas. Marco teórico e referencial: Saúde sexual e saúde reprodutiva de adolescentes e jovens. Brasília, DF: o autor.

Brasil. (2011). Ministério da Saúde, Secretaria de Atenção à Saúde, Departamento de Ações Programáticas Estratégicas. Atenção humanizada ao abortamento: Norma técnica. (2a ed.). Brasília, DF: o autor.

Brasil. (2013). Ministério da Saúde, Secretaria de Atenção à Saúde, Departamento de Atenção Básica. Saúde sexual e saúde reprodutiva. Brasília, DF: o autor.

Brasil. (2010). Ministério da Saúde, Secretaria de Atenção à Saúde, Núcleo Técnico da Política Nacional de Humanização. Ambiência. (2a ed.). Brasília, DF: o autor.

Brasil. (2009). Ministério da Saúde, Secretaria de Ciência, Tecnologia e Insumos Estratégicos, Departamento de Ciência e Tecnologia. 20 anos de pesquisas sobre aborto no Brasil. Brasília, DF: o autor.

Calligaris, C. (2009). A adolescência. São Paulo, SP: Publifolha.

Campos, G. W. S. (2011). A mediação entre conhecimento e práticas sociais: A racionalidade da tecnologia leve, da práxis e da arte. Ciência \& Saúde Coletiva, 16(7), 3033-3040. https://doi.org/10.1590/S1413-81232011000800002

Chatel, M. M. (1995). Mal-estar na procriação: As mulheres e a medicina da reprodução. Rio de Janeiro, RJ: Campo Matêmico.

Católicas pelo direito de decidir. (2016). Uma visão católica a favor do aborto. São Paulo, SP: catolicas.org.br. Recuperado de http://catolicas.org.br/biblioteca/artigos/visao-catolica-a-favor-do-aborto/

Foucault, M. (1998). O nascimento da clínica. Rio de Janeiro, RJ: Forense Universitária.

Foucault, M. (2006). História da sexualidade: A vontade de saber (17a ed., Vol. 1). São Paulo, SP: Graal.

Foucault, M. (2007) Microfisica do poder. São Paulo, SP: Graal.

Foucault, M. (2014). Vigiar e punir: Nascimento da prisão (42a ed.). Petrópolis, RJ: Vozes.

Foucault, M. (2015). Arqueologia do saber (8a ed.). Rio de Janeiro, RJ: Forense Universitária.

Lhullier, L. A., Müller, R. F., Bonassi, B. C., \& Longhini, G. D. N. (2013). Introdução: A pesquisa, seus antecedentes e a proposta que a orientou. In: L. A. Lhullier (Org.), Psicologia: Uma profissão de muitas e diferentes mulheres (pp. 11-20). Brasília, DF: Conselho Federal de Psicologia.

Lhullier, L. A., \& Roslindo, J. J. (2013). As psicólogas brasileiras: levantando a ponta do véu. In: L. A. Lhullier (Org.), Quemé a Psicóloga brasileira? Mulher, psicologia e trabalho (pp. 26-61). Brasília, DF: Conselho Federal de Psicologia.

Martins-Melo, F. R., Lima, M. S., Alencar, C. H., Ramos Jr., N. A., Carvalho, F. H., et al. (2014). Tendência temporal e distribuição espacial do aborto inseguro no Brasil, 1996-2012. Revista de Saúde Pública, 48(3), 508-520. https:// doi.org/10.1590/S0034-8910.2014048004878

Mattos, A. (1994). Alienação no serviço público. Psicologia: Ciência e Profissão, 14(1-3), 28-33. https://doi. org/10.1590/S1414-98931994000100006

McCallum, C., Menezes, G., \& Reis, A. P. (2016). O dilema de uma prática: Experiências de aborto em uma maternidade pública deSalvador, Bahia. História, Ciências, Saúde-Manguinhos, 23(1),37-56. https://doi.org/10.1590/S0104-59702016000100004

McCallum, C., \& Reis, A. P. (2009). Passagem solitária: Parto hospitalar como ritual em Salvador da Bahia, Brasil. In: P. Miranda-Ribeiro, \& A. B. Simão (Orgs.), Qualificando os números: Estudos sobre saúde sexual e reprodutiva no Brasil (pp. 205-231, 2a ed.). Belo Horizonte, MG: ABEP, UNFPA.

Menezes, G., \& Aquino, E. M. L. (2009). Pesquisa sobre o aborto no Brasil: Avanços e desafios para o campo da saúde coletiva. Cadernos de Saúde Pública, 25(2), 193-204. https://doi.org/10.1590/S0102-311X2009001400002 
Pires, T. I. T. (2016). Aborto: Problema legal ou moral? In: V. Zanello, \& M. Porto (Orgs.). Aborto e (não) desejo de maternidade(s): Questões para a psicologia. Brasília, DF: Conselho Federal de Psicologia.

Portaria No 1.459, de 24 de junho 2011. Institui, no âmbito do Sistema Único de Saúde - SUS - a Rede Cegonha. Recuperado de http://bvsms.saude.gov.br/bvs/saudelegis/gm/2011/prt1459_24_06_2011.html

Santos, L. L. N. (2014). Percepções de profissionais de saúde sobre o cuidado ao abortamento em Salvador, BA (Dissertação de Mestrado). Instituto de Saúde Coletiva, Universidade Federal da Bahia, Salvador, BA, Brasil.

Tavares, E. (1996). Mãe Menininha. In: A. I. Tavares (Org.), Mais tarde é agora! Ensaios sobre a adolescência (pp. 101115). Salvador, BA: Ágalma.

Maria Alice Ramos Ferreira Leal

Mestre em Tecnologias em Saúde pela Escola Bahiana de Medicina e Saúde Pública, Salvador - BA. Brasil. Membre Adhérent Praticien da Sociéte de Psychanalyse Freudienne (SPF, 2010). Psicóloga e coordenadora do serviço de Psicologia do Hospital Geral Roberto Santos, Salvador - BA. Brasil.

E-mail: alicefleal@hotmail.com

(iD) https://orcid.org/0000-0001-6129-0273

Marilda Castelar

Doutora em Psicologia Social pela Pontifícia Universidade Católica de São Paulo, São Paulo - SP. Brasil. Professora Adjunta do Programa de Mestrado em Tecnologias em Saúde e do Curso de Psicologia da Escola Bahiana de Medicina e Saúde Pública, Salvador - BA. Brasil.

E-mail: marildacastelar@bahiana.edu.br

(iD https:// orcid.org/0000-0003-1628-6739

Endereço para envio de correspondência:

Rua Professor João José Rescala, 256 B CEP 41720000 Imbuí, Salvador Bahia

Recebido 18/04/2017

Reformulado 14/03/2018

Aceito 04/05/2018

Received 04/18/2017

Reformulated $03 / 14 / 2018$

Aceptado 05/04/2018

Recibido 18/04/2017

Reformulado 14/03/2018

Aceptado 04/05/2018

Como citar: Leal, M. A. R. F., \& Castelar, M. (2019).Abortamento na Adolescência: Atuação de Psicólogas em Hospitais-Maternidade Públicos de Salvador, Bahia. Psicologia: Ciência e Profissão 2019, 39, 1-15. https://doi.org/10.1590/1982-3703003178707

How to cite: Leal, M. A. R. F., \& Castelar, M. (2019).Abortion in Adolescence: Practice of Psychologists in Public Maternity Hospitals in Salvador, Bahia. Psicologia: Ciência e Profissão 2019, 39, 1-15.

https://doi.org/10.1590/1982-3703003178707

Cómo citar: Leal, M. A. R. F., \& Castelar, M. (2019).Aborto en la Adolescencia: Actuación de Psicólogas en Hospitales-Maternidades de Salvador, Bahía. Psicologia: Ciência e Profissão 2019, 39, 1-15.

https://doi.org/10.1590/1982-3703003178707 